PP 12-16

www.iosrjournals.org

\title{
Development and Comparison of Manual Spring Testing Machine with Universal Testing Machine
}

\author{
P. D. Belapurkar, S.D. Mohite, M.V. Gangawane, D. D. Doltode \\ (Department of Mechanical, M.E.S. College of Engineering, S.P. Pune University, India)
}

\begin{abstract}
Mechanical springs used in any machine hold its own stiffness value. This stiffness/ spring rate changes according to different springs and its application. Stiffness of any spring is an important factor as far as its application is considered. Hence in industries many methods are used to test and calibrate springs. Many methods are been used to test springs such as hydraulic actuators or by applying external load etc. In search of the most advanced machinery to test springs, basic mechanisms are under looked. This leads to inefficient growth of machines. Considering this factor manual spring testing machine is developed. No external load, no hydraulic actuators, no external power supply, only use of solid mechanism which lead this machine to apply an external load up to $6000-7000 N$. Only considering one parameter i.e. force applied by a plate on spring leading to deflection. This machine is used to convert circular motion of gears to a linear motion of a plate. Deflection of spring takes place due to force applied by the plate on the spring. Results are compared with UTM. Required modification and optimization is done to optimize the result. This paper illustrates the basic comparison of results of STM with UTM.
\end{abstract}

Keywords - compression spring, helical springs, spring stiffness, spring testing machine, spring rate.

\section{INTRODUCTION}

As predicted by cisco till 2030 there will be more devices online than people, there will be artificial implants for brain, it will take village of human brains to match a $\$ 1000$ computer [1]. In such an environment basic technology is left behind. This technology could lead us to solve difficult algorithms resulting to advanced and more efficient future. This improvement in technology gives precision and accuracy to calculate results and improving the data we have. In search of the most advanced technology, basic mechanisms and algorithms are under looked.

Mechanical springs are one of the oldest technology used in many areas where to and fro motion is required. Springs are used from a push pen to a car's suspension system. Hence springs designing and testing for the required application is important. Before installing, each spring is to be tested. Each spring has its own stiffness value according to its application. Spring is basically an elastic body which compresses if applied compressive load or stretches if applied a tensile load. Its purpose is to distort under load and absorb or release energy according to the conditions [2].

Hence considering all these factors, a manual spring testing machine is designed. A basic factor i.e. deflection due to applied load is used to design this machine. Only a simple mechanism is used to produce required deflection in spring.

\section{SPRING TeSTING MACHINE}

A basic way of testing springs is through Universal testing machine. A hydraulic unit is used to apply load on the spring (compressive or tensile) which results in deflection of spring. A motor supplies an incompressible fluid to hydraulic unit which applies pressure on spring. Hydraulic unit is attached to upper plate whereas lower plate is fix to a base. These plates apply force on any material kept between these two plates. This is an advanced machine which is connected to a computer which takes input as force in newton and after deflection produces results in a form of graph i.e. stress strain graph. [3] Same concept is applied in designing and developing the spring testing machine.

\subsection{Problem Statement}

Spring testing consumes a lot of time, its initial investment is high due to UTM and outsourcing also costs a lot. If initial investments are considered it costs a lot in machinery, maintenance and operating cost. In industries as time is an important component so is the precision and accuracy of results. This level of precision 
Development and Comparison of Manual Spring Testing Machine with Universal Testing Machine

is difficult to achieve and it comes with a cost and time. This machine is designed by considering these important parameters so that springs can be tested in an efficient cost and time.

III. WORKING PRINCIPLE

Helical springs are one of the commonly used springs in industries. These springs are to be designed depending upon force applied in static state. Force is been applied on the spring after lowering the middle plate. This plate applies pressure on the spring which results in compression of spring. Through this compression deflection and spring rate of spring is calculated.

\section{MATHEMATICAL FORMULATION}

The deflection of helical springs can be calculated using deflection-force relation obtained by using Castigliano's theorem [4].

Table-1 Parameters used in equations

\begin{tabular}{|c|l|c|l|}
\hline$U$ & Strain Energy & $F$ & Force applied on the spring, N \\
\hline$T$ & Torque vector, Nm & $D$ & Outer diameter of spring, $\mathrm{mm}$ \\
\hline$L$ & Length of spring wire, $\mathrm{mm}$ & $D$ & Wire diameter of spring, $\mathrm{mm}$ \\
\hline$G$ & $\begin{array}{l}\text { Torsional modulus of } \\
\text { elasticity }\end{array}$ & $A$ & Area of spring, $\mathrm{mm}^{2}$ \\
\hline$J$ & $\begin{array}{l}\text { Polar moment of inertia, } \\
\mathrm{mm}^{4}\end{array}$ & $N_{a}$ & Number of active coils \\
\hline$K$ & $\begin{array}{l}\text { Stiffness of spring, N/mm } \\
\text { na force }\end{array}$ \\
\hline
\end{tabular}
(1):

The total strain energy in the spring wire has two components torsional and shear. They are shown as follows

$$
U=\frac{T^{2} L}{2 G J}+\frac{F^{2} L}{2 A G}
$$

Substituting $T=F D / 2, A=\pi d^{2} / 4, J=\pi d^{4} / 32$ and $L=\pi D N$ in equation (1),

Where $N=N_{a}$ is the Number of active coils, we get:

$$
U=\frac{4 F^{2} D^{3} N}{d^{4} G}+\frac{2 F^{2} D N}{d^{2} G}
$$

Applying Castigliano's theorem to get the deflection " $y$ " in equation (2):

Since $C=D / d$ we can write:

$$
y=\frac{\partial U}{\partial F}=\frac{8 F D^{3} N}{d^{4} G}+\frac{4 F D N}{d^{2} G},
$$

$$
y=\frac{8 F D^{3} N}{d^{4} G}\left[1+\frac{1}{2 C^{2}}\right] \approx \frac{8 F D^{3} N}{d^{4} G}
$$

Knowing that the "spring rate" $k=F / y$

Thus,

$$
k=\frac{d^{4} G}{8 D^{3} N_{a}},
$$

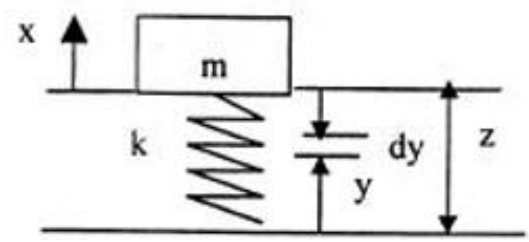

Fig. (1): Spring mass system

The Fig. (1) shows a spring mass system. This system consists of a spring of stiffness $\mathrm{k}$, mass $\mathrm{m}$, the height of spring $\mathrm{z}$ and deflection due to mass $\mathrm{m}$ i.e. $\mathrm{y}[5]$. 


\subsection{System Architecture}

\section{SYSTEM ARCHITECTURE}

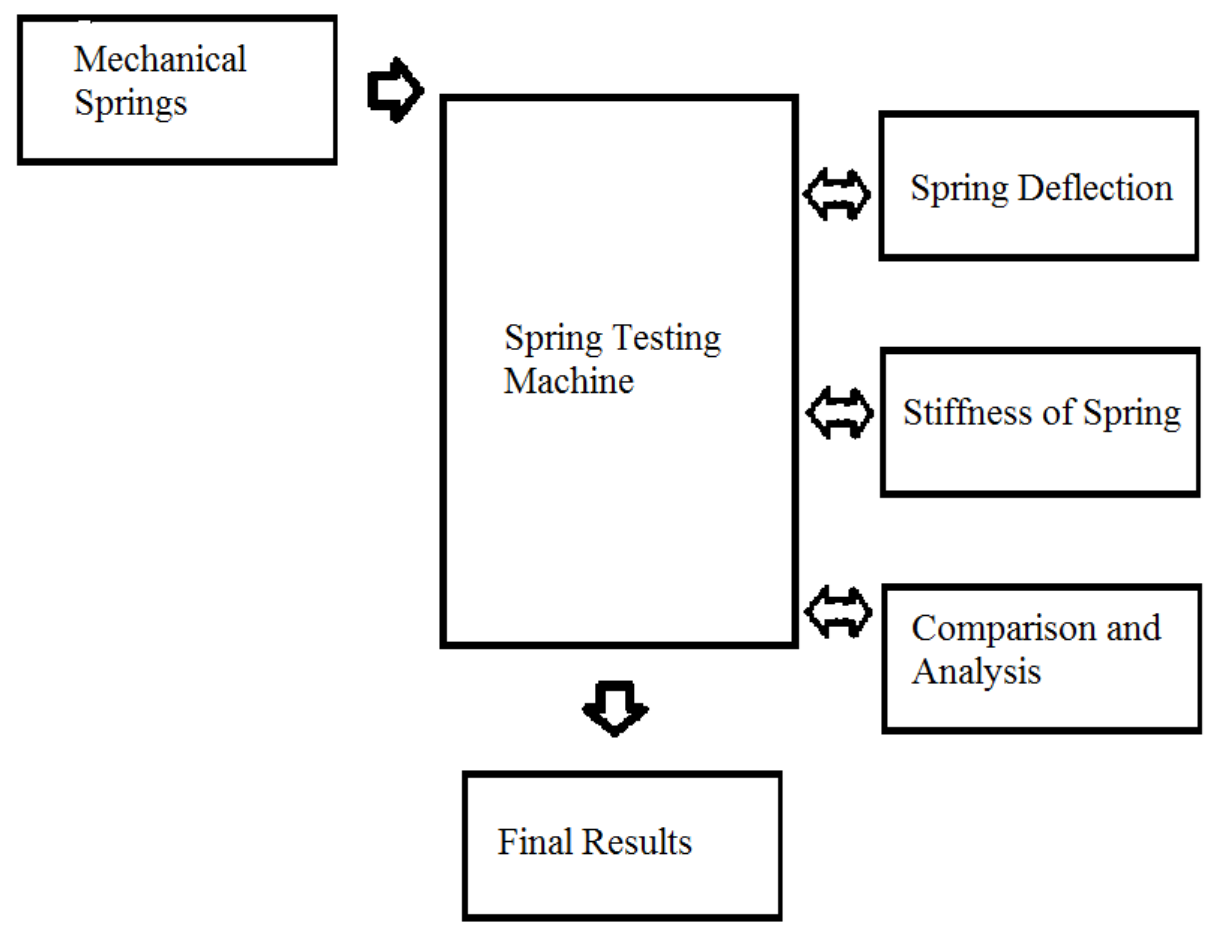

Fig. (2): System architecture

The Fig. (2) shows a system architecture of a spring testing machine. Mechanical spring is the only input given to the machine. After testing springs the output obtained stiffness value/ spring rate, deflection due to force applied. These results can be added to a software for further analysis.

\subsection{System Assembly}

Spring testing machine consists of a base, two side pillars (supporting rods), upper plate, middle plate, bottom plate, two power screw and a load cell. While assembly solid block as a base is installed on the lower plate so that it will create some height for the spring to be tested. Assembly is started by installing two side rods on the bottom plate. The middle plate is inserted through the rods and rests on the base till upper plate and power screws are installed. Then the upper plate is riveted to the rods with hexagonal nuts. Then power screws are installed with gears. These plates are installed in such a way that both the upper plate and the middle plate are parallel to each other. Then after the entire assembly load cell is installed on the base to calculate the weight and force applied on the spring. Spring to be tested is fixed between the base and the middle plate.

\subsection{Operation of the System}

Spring to be tested is fixed between the middle plate and the base. Base has a load cell connected which displays the force applied on a LED screen. The upper plate has three gears installed on the top. These gears are meshed to each other. Two of these gears are connected to a power screws. Which directs the middle plate in the downward direction. The middle gear transmit power between these two gears. The upper plate and the bottom plate are fixed, hence they cannot move in upward or downward direction. When one of the meshed gear is rotated the center gear rotate in other direction. Hence both the gears rotate in the same direction. This results in the downward movement of the middle plate. When a spring is kept between middle plate and the base, the spring gets compressed due to downward motion and spring gets deflected. Load cell displays the load applied on the spring in $\mathrm{kg}$. A difference between the upper plate and the middle plate is checked through a 
Development and Comparison of Manual Spring Testing Machine with Universal Testing Machine

displacement sensor, depth gauge or a Vernier caliper. A difference between these two plates gives the deflection of spring in mm. Minimum 10-15 readings are recorded to calculate stiffness value. This reduces the errors in the readings recorded.

\section{TESTS AND RESULTS}

The tests were carried on various sizes of springs. Same springs were tested on both spring testing machine and universal testing machine. Comparisons of these results were used to calibrate manual spring testing machine. Few changes were made with the help of these results. Following are the results obtained on both the machines:

STM = Spring testing machine

$\mathrm{UTM}=$ Universal testing machine

Table - 2: Readings of comparison of loads and extensions between STM and UTM

\begin{tabular}{|c|c|c|c|c|}
\hline Extension $(\mathrm{mm})$ & Force $(\mathrm{kg})$ & Force $(\mathrm{N}) \mathrm{STM}$ & Force $(\mathrm{kg})$ & Force $(\mathrm{N})$ UTM \\
\hline 0 & 0 & 0 & 0 & 0 \\
\hline 1 & 25.1 & 246.2 & 26.7 & 262.5 \\
\hline 2 & 55.6 & 545.4 & 53.51 & 525 \\
\hline 3 & 84.1 & 825.02 & 76.4 & 750 \\
\hline 4 & 115.6 & 1134.03 & 107.03 & 1050 \\
\hline 5 & 146.8 & 1440 & 138.4 & 1357.5 \\
\hline 6 & 177.1 & 1737.3 & 169.7 & 1665 \\
\hline 7 & 209.2 & 2052.2 & 201.8 & 1980 \\
\hline 8 & 242.2 & 2375.9 & 233.2 & 2287.5 \\
\hline 9 & 276.3 & 2710.5 & 265.3 & 2602.5 \\
\hline 10 & 309.8 & $3039 . .1$ & 298.9 & 2932.5 \\
\hline 11 & 343.5 & 3369.73 & 330.3 & 3240 \\
\hline 12 & 378.5 & 3713 & 362.4 & 3555 \\
\hline 13 & 413.1 & 4052.5 & 394.5 & 3870 \\
\hline 14 & 445.89 & 4374.1 & 425.8 & 4177.5 \\
\hline 15 & 485.2 & 4759.8 & 458.7 & 4500 \\
\hline 16 & 522.2 & 5122.8 & 490.8 & 4815 \\
\hline 17 & 561.2 & 5505.4 & 522.9 & 5130 \\
\hline 18 & 597.3 & 5859.5 & 555.8 & 5452.5 \\
\hline 19 & 635.1 & 6230.3 & 588.7 & 5775 \\
\hline 20 & 673.5 & 6607 & 619 & 6075 \\
\hline
\end{tabular}

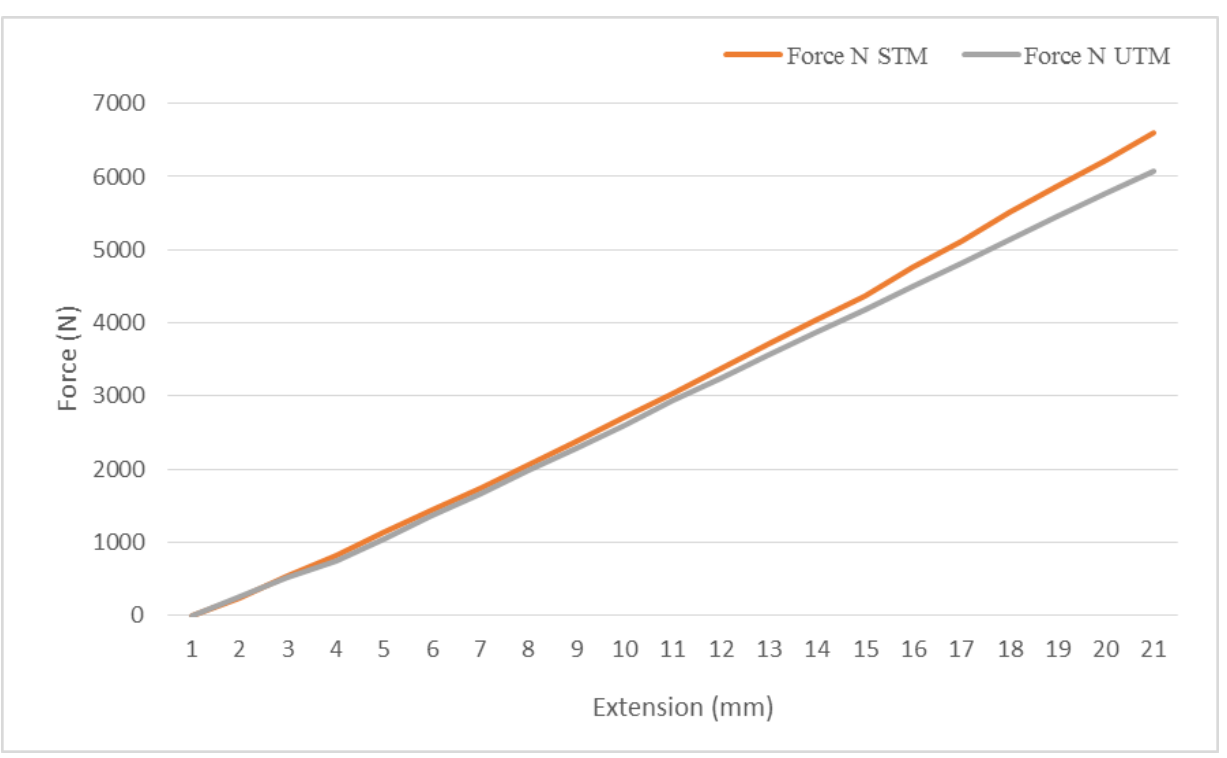

Fig. 3: graph of Force (N) vs Extension (mm) 
Fig. 3 shows a graph of comparison between universal testing machine and spring testing machine. It is observed that both the readings show significant similarities. But as the graph shows as the force $(\mathrm{N})$ and extension $(\mathrm{mm})$ increases there is a gradual increase in their difference.

\section{CONCLUSION}

Every spring has its own unique stiffness value which varies according to the material and its application. Spring stiffness is an important performance characteristic which is required for its application. As the above readings show the results obtained are precise. Testing basically consists of tolerances. The springs are accepted or rejected depending upon the precise data and analysis. The above readings show a significant result which are on average $94.37 \%$ accurate with reference to the universal testing machine. Precise results are obtained, but improvements can be done to obtain accurate results.

\section{FUTURE SCOPE}

There is a tremendous amount of scope as far as this mechanism is considered. This is the most basic way of testing springs. Automation is an area where this machine can evolve and can be used to measure stiffness of other springs and materials e.g. Rods, blocks etc. Some of the basic improvements that can be done in the machine and the mechanism are given below:

Optimisation of the machine

Cost of the machine can be reduced by optimization. As the machine weights from $90-100 \mathrm{~kg}$, the thickness of plates can be reduced and I section clamps can be added to reduce its weight. Use of different material for manufacturing, four small bars instead of two solid bars can be used to reduce material, weight of machine. Similar methods can be practiced to optimize the machine.

\subsection{Sensors for testing}

Different sensors and measuring devices can be used to obtain the readings of spring displacement. In this machine Vernier calliper or depth gauges are used to obtain the readings. Due to use of Vernier calliper manmade errors can occur when readings are taken. Hence sensors like displacement sensors, LVDT's can be used. Use of these sensors will reduce manmade errors.

\subsection{Improvement by adding fixtures}

Improvements can be done by adding fixtures to machine which will improve the accuracy of results obtained. Fixtures can distribute the force applied on the machine which will result in reduction of errors.

Mechanical spring is also an important factor considered when this machine is designed. Depending upon the required operation different materials are used for designing springs, as far as the material used is elastic and rigid [3]. Use of these materials can result in waring of machine. To avoid this waring and consistent use of this machine fixtures and easily available parts can be used.

\section{Acknowledgements}

We reserve our sincere thanks to our guide Prof. Sushant. S. Jadhav for his endless encouragement and assistance all throughout.

\section{REFERENCES}

[1] D. Evans, Top 25 technology predictions, cisco IBSG innovations practice, Cisco IBSG 2009.

[2] P. Belapurkar, S. Jadhav, A new Methodology for Testing Spring Stiffness, IJSR, Nov 2015.

[3] S. Matsumoto, H. Miyashita, K. Tashiro K. Murauchi, M. Kakuta, Sagamihara-shi, Hydraulic system and universal testing machine, US Pate nt application publication Matsumoto et al, Mar 1, 2012.

[4] R. G. Budynas and J. Keith Nisbett, Shingley’s Mechanical engineering design, $9^{\text {th }}$ edition, (McGraw) 2011.

[5] V. B. Bhandari, Design of Machine elements, $4^{\text {th }}$ edition. 